\title{
$\operatorname{arCOS} D E S I G N$
}

\section{A gestão dos conflitos de interesses em equipes de design gráfico conforme as teorias sobre a tomada de decisão}

\author{
Eugenio Andrés Diaz Merino (UFSC, Brasil) \\ eugenio.merino@ufsc.br \\ Igor Reszka Pinheiro (UNIFEBE, País) \\ pinheiro_ir@yahoo.com.br \\ Luiz Salomão Ribas Gomez (UFSC, País) \\ salodesigner@gmail.com
}




\title{
A gestão dos conflitos de interesses em equipes de design gráfico conforme as teorias sobre a tomada de decisão
}

Resumo: Este artigo, após constatar a inexistência de métodos capazes de resolver os conflitos de interesses e favorecer a noção de pertencimento em projetos colaborativos, apresenta os pressupostos teóricos de um novo processo para a gestão dessas equipes de design. Para tal, escrutina-se, por meio de um ensaio crítico de natureza exploratória, os fundamentos cognitivos da tomada de decisão. A solução proposta consiste de uma heurística de rotatividade do poder de decisão central, seguindo as mesmas perspectivas empregadas no Balanced Scorecard.

Palavras-chave: equipes de design; conflitos de interesses; tomada de decisão.

\section{Conflict of interests management in graphic design teams according to the decision making theories}

\begin{abstract}
This paper discusses the lack of methods capable of both avoiding conflicts of interest and promoting engagement in collaborative projects, and presents the theoretical background of a new process for managing design teams. In order to do that, it is performed an exploratory literature review aiming at disentangle the cognitive fundamentals of decision making. The proposed solution consists of sustaining the change in the decision power, which follows the same perspectives of the Balanced Scorecard.
\end{abstract}

Keywords: design teams; conflict of interests; decision making. 


\section{Introdução}

O matemático norte-americano John Nash, em sua representação cinematográfica perpetrada no filme Uma Mente Brilhante, teve a sua ideia de equilíbrio para a teoria dos jogos com base na seguinte observação feita em um bar: se todos os homens tomarem a iniciativa de cortejar somente a mulher mais bonita do ambiente, no máximo um deles seria contemplado com a sua companhia e nenhum dos demais estaria apto para se aproximar de outras moças, já que essas ficariam ofendidas em serem abordadas somente como uma segunda opção. Seja essa epifania verídica ou não, o fato é que a lição presente nesta passagem é logicamente válida para a maioria dos contextos de recursos finitos: em um grupo qualquer, se cada indivíduo buscar exclusivamente o que é melhor para si mesmo, existe grande chance da coletividade como um todo ser prejudicada (HARDIN, 1968). Para se maximizar os ganhos ou os resultados, não só do grupo como um todo, mas, também, de cada sujeito desses ambientes, é necessário, então, uma estratégia superordenada (SHERIF, 1958). É necessário um método coletivo para equilibrar as partes e, assim, evitar os conflitos de interesses.

Conflitos de interesses não são obra de ficção. Eles estão sempre presentes no trabalho de equipes multidisciplinares, sobretudo naquelas envolvidas com problemas pouco estruturados, como é o caso do design. Nessa área, mesmo quando o objetivo final do trabalho está suficientemente bem definido, os diferentes jargões, culturas e requisitos técnicos das inúmeras especialidades envolvidas em um projeto, frequentemente, impelem seus representantes a elencarem prioridades ou necessidades divergentes (SHIH; HU; CHEN, 2006; WONG; LAM; CHAN, 2009). Enquanto para uns, por exemplo, os requisitos de espaço da parte elétrica de um projeto são prioridade, para outros, os requisitos de manuseio da parte ergonômica desse mesmo projeto estão acima dos demais critérios (KLEINSMANN; VALKENBURG, 2008). Nenhum dos dois lados neste caso, e em tantos outros, está necessariamente certo, ou mesmo mais certo, eles apenas valorizam diferentes aspectos, sensações, conceitos ou noções do mesmo produto ou processo que se deseja ofertar ao público.

Destarte, o problema de se decidir por um ou outro valor conflitante na área do design emerge, justamente, do fato de que, na maioria das vezes, eles são fundamentalmente distintos e, portanto, irredutíveis a uma métrica comum (SHIH; HU; CHEN, 2006; WONG; LAM; CHAN, 2009). Não é possível aferir objetivamente, por meio de uma única unidade de medida, ergonomia e consumo de energia, inovação e economia, 
satisfação do cliente e impacto na ecologia, inteligibilidade e grau de simpatia e tantos outros valores, por vezes, contraditórios em um projeto de design. Nisso, a única solução até então oferecida para esses persistentes conflitos de interesses é a hierarquização subjetiva das diferentes crenças ou vontades individuais presentes em cada uma das etapas projetuais (AMABILE, 1982; BAXTER, 1998; FUENTES, 2006; PHILLIPS, 2008; YANG, 2010).

Em termos práticos, hierarquizar ou centralizar indivíduos em uma rede social consiste, basicamente, do ato de se definir lideranças. Se dois ou mais projetistas discordam a respeito de algum assunto irredutível, basta que se recorra à intervenção do indivíduo que se configura como o seu elo de ligação para que se chegue a uma conclusão, pois, em última instância, é ele quem detém o poder de decisão. Nisso, equipes de design centralizadas, tanto em teoria (JACKSON; WOLINSKY, 1996) quanto na prática (YANG, 2010), são sempre consideradas mais ágeis e, por conseguinte, eficientes, já que a sua atuação em torno de uma única vontade tende a concentrar os esforços coletivos e, ainda, a reduzir o tempo despendido em debates puramente opinativos. Tal solução para os conflitos de interesses não é ideal, pois, na medida em que se forma uma liderança, a mesma diferenciação entre as partes que facilita o processo de tomada de decisão também tende a fragilizar a noção de pertencimento dos indivíduos periféricos de uma coletividade, o que a longo prazo promove, ou o seu afastamento do grupo, ou a redução de sua produtividade (YANG, 2010).

Conforme a linha de estudo da psicologia social, o que torna paradoxal a resolução de conflitos de interesses por meio da centralização de um ator é o fato de que apesar da figura do líder servir, prioritariamente, como elemento de sustento da cooperação, ela invariavelmente também gera a sua antítese, a competição, uma vez que se reduz a capacidade de diálogo dos agentes periféricos e se fomenta as ações voltadas exclusivamente para a conquista dessa única e indivisível posição de destaque (CHERRINGTON, 1973; MCCALLUM et al., 1985). Como se pode observar na Figura 1, a configuração centralizada de um grupo qualquer (c), não é apenas aquela com menos vínculos entre os seus atores periféricos, como também é a única em que existe uma nítida diferenciação entre as posições estruturais (círculos brancos e preto). Assim, se por um lado, tal configuração é a que mais agiliza o fluxo de informação, por outro, ela também é a mais suscetível a uma possível fragmentação.

Desse modo, uma das principais questões ainda pendentes no processo de gestão de equipes internas de design é o trade-off entre a permanência dos mesmos projetistas em uma organização, o que possibilita 
ganhos gerais pela melhora na curva de aprendizado, e a eficiência da atual equipe como um todo, o que gera ganhos pela maior velocidade na conclusão dos projetos. Deve-se priorizar as estruturas de tomada de decisão consensuais (Fig. 1a), nas quais todos têm pleno poder de veto? Deve-se priorizar as estruturas de tomada de decisão centralizadas (Fig. 1c), nas quais somente um indivíduo é responsável pelo resultado final? Ou deve-se priorizar um meio termo, as estruturas de tomada de decisão democráticas (Fig. 1b), nas quais todos compartilham apenas o poder de voto?
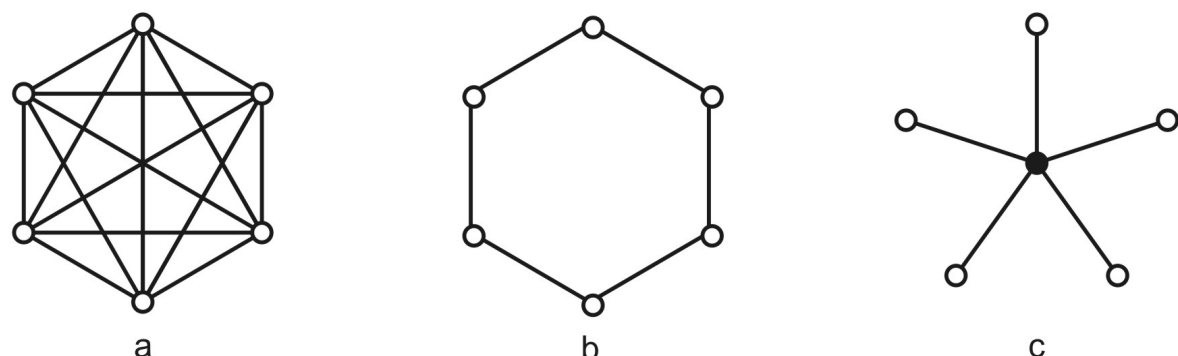

b

C

Figura 1. Redes Sociais Consensual (a), Democrática (b) e Centralizada (c) Fonte: Autor

Dada a inexistência de métodos capazes de, simultaneamente, resolver os conflitos de interesses e favorecer a noção de pertencimento das equipes internas de design, este artigo tem como objetivo, então, apresentar os pressupostos teóricos de uma possível solução para a gestão de projetos colaborativos. Por meio de um ensaio crítico de natureza exploratória (MARCONI; LAKATOS, 2007), revisou-se a literatura sobre os processos de tomada de decisão individual e coletiva, para dar os primeiros passos rumo à estruturação sistemática do equilíbrio dinâmico entre as diferentes vontades das partes interessadas em projetos, sobretudo da área gráfica. A exemplo de outros autores desta área (SHIH; HU; CHEN, 2006), acredita-se que, com base nas elaborações de John Nash sobre a teoria dos jogos, é possível promover um sistema estratégico de tomada de decisão capaz de manter a cooperação sem que se iniba o impulso individual de maximizar a própria satisfação.

\section{Teorias sobre tomada de decisão}

Tomada de decisão é um termo genérico que se refere ao processo de selecionar uma opção em particular dentre uma série de alternativas, cujos resultados, teoricamente, produzem diferentes consequências, sejam elas positivas, negativas ou neutras (LEE, 2013). Apesar desse processo 
frequentemente empregar o raciocínio como ferramenta de equiparação das diferentes alternativas, ele não necessariamente se baseia em um juízo crítico, ou seja, em algoritmos mentais de validação das premissas empregadas para sustentar cada escolha, mas sim em heurísticas parciais que equacionam os seus custos aparentes em função do tempo necessário para se obter alguma vantagem ou utilidade (MATLIN, 2004). Nisso, pode-se dizer que a tomada de decisão é um processo probabilístico, o qual se baseia tanto em dados sensoriais, quanto na média, na frequência, na proximidade e na recenticidade de eventos passados para se projetar cenários futuros e, assim, fazer escolhas adequadas (BOGACZ, 2006; MATLIN, 2004).

Atualmente, encontram-se disponíveis, basicamente, dois modelos que visam explicar a tomada de decisão em termos neurológicos (BOGACZ, 2006): 1) o modelo de processamento concorrente (race model); e 2) o modelo de processamento por difusão (diffusion model). Conforme exibe a Figura 2, enquanto o primeiro modelo compreende a escolha como o acúmulo paralelo de evidências favoráveis a uma ou outra alternativa até que a primeira delas supere o limiar de inibição comportamental definido pelos gânglios basais (corpo estriado, globo pálido, substância negra e núcleo subtalâmico), o segundo também visa a superação desse mesmo limiar inibitório, porém, este pela soma das características antagônicas das possíveis alternativas. A despeito de suas diferenças, o que ambos esses modelos têm em comum são os pressupostos de que a percepção das múltiplas alternativas disponíveis depende da integração sensorial e mnemônica ocorrida sobretudo no córtex pré-frontal (círculos na Fig. 2) e, também, a ideia de que a "escolha" padrão dos seres humanos é sempre a inibição (setas pretas na Fig. 2). Existem inúmeros experimentos que suportam esses dois pressupostos, os quais se deflagram principalmente por déficits cognitivos provocados pelo autismo e pelo mal de Parkinson, pela desinibição gerada pela ação química do uso de drogas e pelo estudo imagético, por meio de ressonância magnética funcional (fMRI), da ativação sináptica dos vieses comportamentais (BOGACZ, 2006; DE MARTINO et al., 2006; LEE, 2006, 2013).

Apesar do modelo de processamento concorrente ainda ser amplamente utilizado para investigar fenômenos relacionados às teorias neoclássicas da tomada de decisão, existe cada vez mais indícios de que o modelo de processamento por difusão é o mais adequado para descrever e prever a tomada de decisão naturalística tipicamente descrita pelas teorias comportamentais (BOGACZ, 2006; DE MARTINO et al., 2006). O mais evidente desses indícios possivelmente é o bastante replicado paradoxo de Allais, o qual demonstra que, na prática, os seres humanos são avessos ao 
risco em relação aos seus ganhos, porém, são propensos ao risco em relação às suas perdas de mesma magnitude (ALLAIS, 1953; DE MARTINO et al., 2006; LEE, 2006). Isso significa que, na média, aceita-se pequenos ganhos no lugar de ganhos maiores, porém, incertos, mas recusa-se pequenas perdas se houver a chance de nenhuma perda, mesmo que esta última alternativa também possibilite perdas potencialmente mais elevadas.

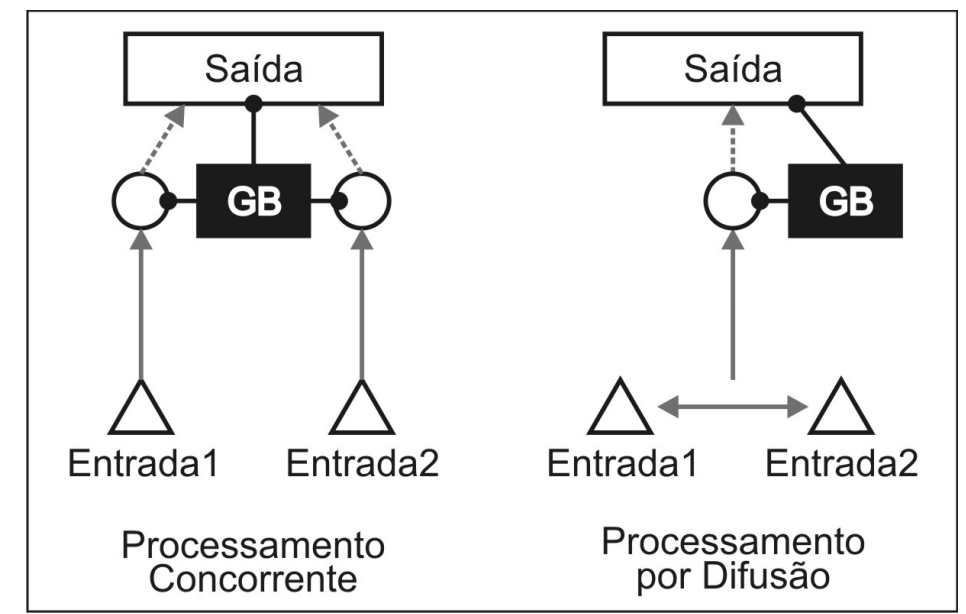

Figura 2. Modelos Neurológicos do Processo de Tomada de Decisão [GB: Gânglios Basais; Fonte: Autor, com base em Bogacz, 2006]

Esse relaxamento, ou distorção, do axioma normativo de máxima utilidade, além de atuar como um mecanismo de defesa que impede a adoção de comportamentos coletivos excessivamente reticentes capazes de promover a extinção da espécie, torna a tomada de decisão um processo mais ágil, o que também se caracteriza como uma vantagem evolutiva (LEE, 2013; MCCALLUM et al., 1985). É mais rápido definir uma ação ótima pela soma de sua possível utilidade com os custos percebidos das demais alternativas, que pelo aglutinamento isolado dessas mesmas variáveis para cada opção. Desse modo, o tomador de decisão, mais que se tornar capaz de escolher também com base naquilo que ele não quer, libera chunks de sua memória de trabalho para realizar previsões mais complexas, dado que aproveita-se uma vez só para as diferentes alternativas os dados antes redundantes.

O modelo de processamento por difusão, assim como o modelo de processamento concorrente, aceita, então, a premissa básica do dito homo economicus, a qual prega que a razão psicológica essencial do ser humano é o interesse próprio, porém, vai além deste, ao computar as escolhas com base em um ponto de referência relativo que pondera as probabilidades por meio de uma função não linear, conforme proposto pela teoria da prospecção (KAHNEMAN; TVERSKY, 1979; LEE, 2006). Por essa perspectiva, a aversão 
humana às perdas enverga a função de utilidade percebida de cada opção em um momento de tomada de decisão, tornando assimétrica a medida dos custos e dos benefícios de se adotar uma postura arriscada (Fig. 3). Nisso, dado o conhecimento de todas as probabilidades de uma escolha, o ser humano tende a se ater à alternativa que estiver mais acima da curva de indiferença que corta o primeiro e o terceiro quadrante trigonométrico exibido pela relação de ganhos e perdas na Figura 3 (KAHNEMAN; TVERSKY, 1979).

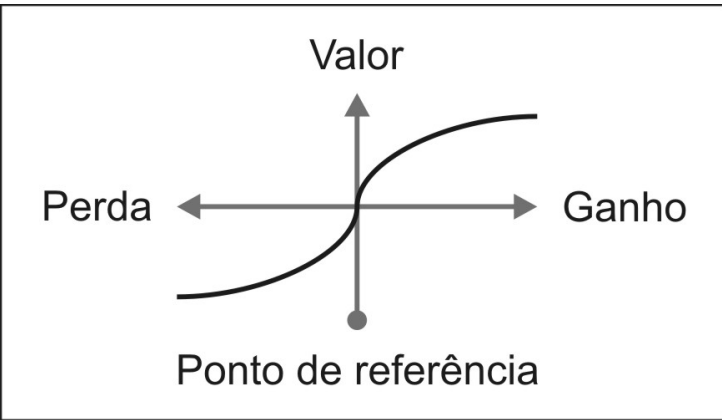

Figura 3. Curva de Utilidade da Tomada de Decisão Fonte: Autor, com base em Lee, 2013

O principal fator que torna difícil realizar uma boa escolha individual é, então, o desconhecimento das probabilidades de ganho e perda das possíveis alternativas, já que isso impossibilita a demarcação adequada de um ponto referencial. Este norte conceitual, depende não apenas do manejo cognitivo dos vieses de representatividade, ancoragem, enquadramento e disponibilidade (MATLIN, 2004), mas também, e sobretudo, do contexto social (LEE, 2013). Quanto mais atores estiverem envolvidos em um processo de tomada de decisão, seja ele coletivista, seja ele por exclusão, menos se sabe individualmente a respeito das probabilidades associadas a uma dada opção. Em qualquer um desses casos, o aumento no número de pessoas interessadas faz com que não se saiba, em geral, a chance de que uma mesma escolha ótima para um indivíduo coloque outro sujeito em uma posição mais ou menos privilegiada na rede de relações sociais, o que pode desencadear movimentos perpétuos em um jogo de interesses. Para a teoria dos jogos, essa situação corresponde à ausência de um equilíbrio de Nash (1951).

Um exemplo bastante ilustrativo desse tipo de problema investigado pela teoria dos jogos é a tomada de decisão individual em uma competição de combinar moedas (matching pennies). Nessa atividade, dois sujeitos devem escolher entre cara ou coroa; se ambos escolherem cara ou se ambos escolherem coroa, um deles ganha, mas se cada um escolher uma 
face diferente, cara e coroa ou coroa e cara, o outro ganha. Dadas essas regras, conforme exibe a Figura 4, não existe um ponto de referência fixo para que qualquer um dos atores seja capaz de realizar uma escolha ótima, pois, no momento em que se faz qualquer escolha, a reação alheia tende a tornar essa mesma escolha desvantajosa. Se, então, o sujeito que ganha com as faces idênticas optar, por exemplo, por iniciar a atividade pela alternativa cara, o outro ator desse sistema irá optar por coroa, o que forçará o primeiro deles trocar a sua escolha para coroa também, desencadeando um ciclo sem fim de ajustes das decisões.

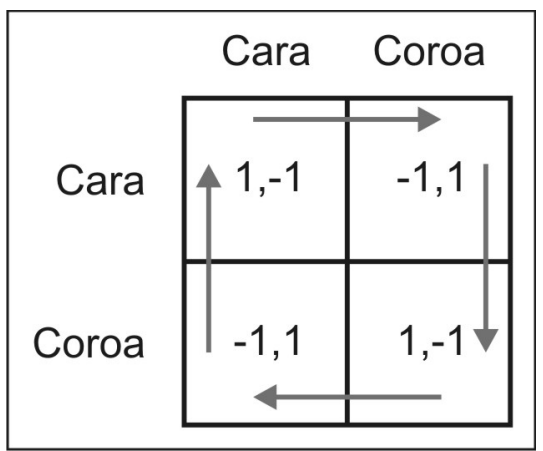

Figura 4. Dinâmica do Jogo de Combinar Moedas. Fonte: Autor

De acordo com a teoria dos jogos, em toda atividade competitiva, ou seja, em toda interação cujos valores ou utilidades gerais possuem soma zero, não existe, portanto, decisão individual ótima por si só, pois, não há forma de se tornar os ganhos individuais independentes das demais escolhas gerais (BLOCH; JACKSON, 2006). O único ponto de referência teoricamente sustentável para esse tipo de sistema é a manutenção da própria inércia rotativa de ganho e perda ao longo de múltiplas sessões de jogos, o que tornaria a dinâmica social uma constante passível de equacionamento para a tomada de decisão. Neste caso, opta-se ou por participar da dinâmica, pois extrai-se utilidade do próprio processo de interação, ou por excluir-se da dinâmica, já que não se percebe valor objetivo algum para motivar os possíveis custos de uma interação social (HARRIS, 1993).

Determinar se uma escolha é potencialmente vantajosa ou não a nível individual em qualquer dinâmica social, depende, então, primeiramente da probabilidade de que a utilidade gerada pela sinergia da coletividade será maior, menor ou igual aos custos de se pertencer a essa mesma macro-entidade (JACKSON; WOLINSKY, 1996). Se o resultado dessa equação indicar que o custo de se inserir em um sistema social é muito elevado, a escolha ótima é permanecer isolado; se indicar um custo muito reduzido, a escolha ótima é tornar-se plenamente conectado (Fig. 1a); e se 
indicar um custo mediano, a escolha ótima é buscar, sempre que possível, um grupo centralizado (Fig. 1c). Tais conclusões se baseiam no fato de que o interesse próprio em se manter socializado é potencializado sobretudo pela soma da utilidade indireta (sinergia) de um sistema qualquer, mas normalmente é penalizado somente pelos custos diretos de interação, o que privilegia os arranjos, simultaneamente, com máxima participação e com mínima conectividade (BLOCH; JACKSON, 2006; JACKSON; WOLINSKY, 1996).

Destarte, a tendência individual de tomar decisões, sobretudo com base na utilidade advinda da estabilidade de alguma interação direta, se desdobra em uma tendência coletiva de se organizar em grupos centralizados, dos quais também se extrai considerável utilidade pela eficiência ótima de sua sinergia estrutural. Conforme o modelo matemático proposto por Jackson e Wolinsky (1996) para descrever a utilidade de uma rede social, o único problema das redes centralizadas é, todavia, o fato de que, apesar delas oferecerem o máximo de utilidade (Pareto efficiency), elas dificilmente possuem vínculos entre pares com alto nível de estabilidade (pairwise stability). Havendo vínculos individualmente vantajosos, as redes tenderão, invariavelmente, à hiperconectividade. Nisso, decisões baseadas puramente no interesse individual se mostram essencialmente incapazes de equilibrar a permanência dos indivíduos em um determinado grupo com a eficiência desse mesmo grupo.

Com base nessa racional, compreende-se, então, que a formação e a manutenção espontânea de sistemas centralizados, em contextos de recursos finitos, só ocorrerá nos casos em que se faz necessária a cooperação interna para se obter vantagem competitiva contra ameaças externas potencialmente mais custosas que os benefícios percebidos pelos atores periféricos em seu próprio sistema. Tais ameaças podem consistir tanto da falta de recursos disponíveis para a coletividade (HARDIN, 1968; RENEKE, 2009), como água em um deserto ou dinheiro em uma empresa, quanto da presença de outros sistemas concorrentes (MCCALLUM et al., 1985; SHERIF, 1958), como exércitos rivais ou indústrias de produtos substitutos. Nesses casos, a decisão individual de confiar os recursos gerados pela sinergia coletiva a um único líder central costuma compensar a certeza de alguma perda real, pois, conforme dito anteriormente, os seres humanos só são propensos ao risco nos casos de prejuízo em potencial.

Sendo assim, com exceção dos casos em que as decisões individuais não reverberam absolutamente em nenhuma de suas estruturas sociais, toda escolha humana se baseia, fundamentalmente, na delimitação de um ponto referencial que indica a probabilidade dos seus interesses imediatos serem 
supridos pela manutenção de uma determinada posição estrutural. Se um indivíduo qualquer estiver imediatamente interessado em algum ganho particular, conforme exibe a Figura 3, suas decisões privilegiarão os comportamentos seguros, os quais, em termos sociais, equivalem à desconfiança entre pares e, portanto, aos conflitos estruturais. Já se, por outro lado, um indivíduo qualquer estiver imediatamente interessado em evitar perdas, conforme também exibe a Figura 3, suas escolhas favorecerão os comportamentos arriscados, como confiar em seus pares, e, por conseguinte, à observância estrutural.

Nisso, percebe-se que as teorias sobre tomada de decisão, apesar de transparecerem uma solução satisfatória para os conflitos de interesses entre pares, não oferecem, em si, sugestões conclusivas para o problema de se equilibrar a eficiência de um todo social com a satisfação de suas partes individuais. A manutenção da inércia de um relacionamento diádico pelo contínuo espelhamento das decisões alheias (Fig. 4), ou seja, "fazer com o outro o que ele faz com você", é uma estratégia ótima para se garantir a máxima utilidade nas interações diretas (FUDENBERG; MASKIN, 1986; SANDRONI, 1998), mas não sustenta formações centralizadas, já que estas requerem a aceitação de riscos, ou seja, confiar no outro. A resolução dos conflitos de interesses entre as partes e o todo de um sistema social qualquer, em ambientes com recursos finitos, requer, então, um método externo capaz de conciliar a tendência de maximizar a utilidade em cada escolha ou estratégia individual com os ganhos de eficiência geral.

\section{Uma proposta para gerir os conflitos de interesses em equipes de design gráfico}

Em projetos colaborativos de design gráfico, assim como em qualquer outro contexto de recursos finitos, as decisões individuais baseiam-se, sobretudo, na probabilidade de que a utilidade obtida pelo favorecimento dos interesses próprios é maior que utilidade obtida pelo favorecimento dos interesses de outrem. Nisso, confiar nas decisões alheias só é particularmente vantajoso na medida em que o valor agregado ao produto ou processo final (sinergia projetual) é suficientemente grande para, mesmo sendo desigualmente compartilhado, compensar os riscos adotados. Abrir mão de alguma ideia ou critério levantado em favor de outro projetista cooperado deve, então, se provar ou financeiramente compensador ou, ainda mais, um recurso necessário para o enfrentamento de outro grupo competidor. 
Dentre as diferentes perspectivas internas de uma equipe de design gráfico, a opção padrão resultante das decisões individuais tende a convergir, portanto, em uma das duas diretrizes centrais voltadas para as atuais contingências ambientais: 1) No caso de contextos estáveis, a tendência individual será privilegiar os ganhos seguros, os quais correspondem principalmente ao lucro; e 2) No caso de contextos instáveis, a tendência individual será privilegiar a vertente com maior capacidade de adaptação, ou seja, de promover a inovação. Destarte, sempre que não houver uma liderança externa que determine a priori os critérios da estratégia geral, toda proposição individual em um projeto será avaliada pelos demais membros do grupo como uma alternativa segura capaz de sustentar a atual estrutura coletiva de poder centrada na perspectiva financeira, ou como uma opção arriscada capaz de modificar tal estrutura pela promoção de uma das outras perspectivas periféricas.

Tais conclusões gerais, derivadas do próprio processo que conduz as decisões individuais, contradizem, contudo, os atuais métodos coletivos empregados para gerir o equilíbrio dos interesses em equipes de design gráfico. Em um dos mais proeminente desses métodos, o Balanced Scorecard (BSC), percebe-se, por exemplo, que a diretriz geral empregada para equilibrar a estrutura social é o emparelhamento das diferentes perspectivas internas da equipe projetual, e não a manutenção ou a promoção de um elemento central (WONG; LAM; CHAN, 2009). Nisso, como se observa na Figura 5, a organização das equipes internas de design, de acordo com o BSC, tenderia à forma de uma rede social democrática (Fig. 1b), na qual todas as suas quatro perspectivas possuem o mesmo peso ou poder de voto nos momentos de decisão coletiva.

Os problemas dessa típica forma de organização das equipes de design gráfico são, entretanto, facilmente constatados com base nas teorias sobre a tomada de decisão. Primeiro, existe o fato de que as estruturas democráticas não são, em geral, tão eficientes quanto as suas concorrentes centralizadas, o que as faria perecer em um ambiente de recursos finitos, como é o caso dos investimentos no mercado de design. Segundo, ignorando o princípio da escolha por vínculos que maximizem a satisfação dos interesses próprios, essa estrutura abre margem para a formação de alianças políticas informais, as quais distorcem a sua verdadeira face democrática e, portanto, a sensação de justiça e pertencimento das perspectivas vencidas por votação. E, terceiro, tais formações organizacionais, exemplificadas perfeitamente pelo BSC (Fig. 5), necessitam de critérios ou pontos de vista externos (top-down) para que haja a observância das estratégias conjuntas por parte de seus atores (bottom-up), o que caracteriza uma incompletude 
sistêmica ou, em outras palavras, uma equipe incapaz de auto-sustentar o seu conjunto de escolhas.

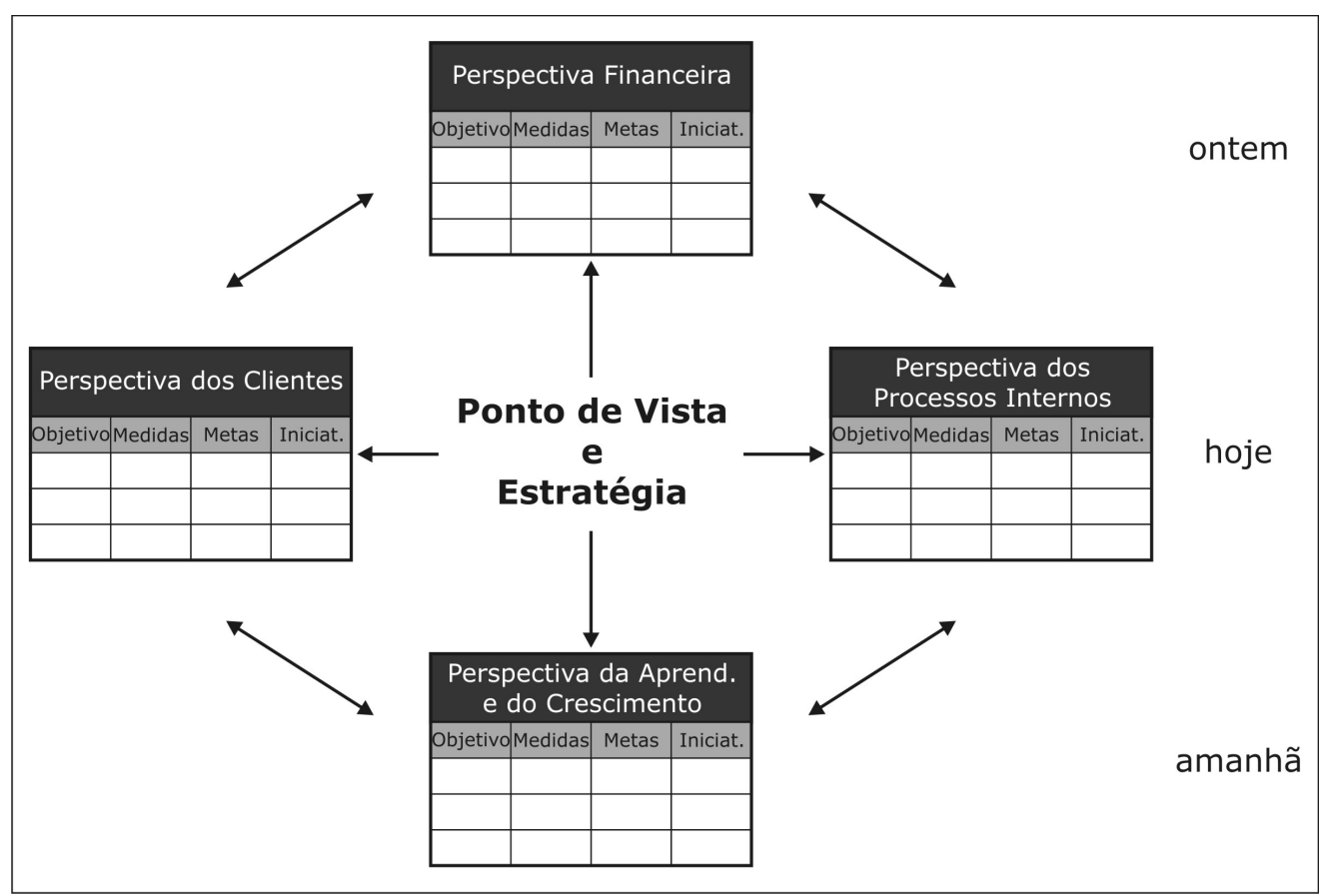

Figura 5. O Balanced Scorecard. Fonte: Autor, com base em Rodrigues, 2006.

Nisso, propõe-se que o equilíbrio dos diferentes interesses em equipes de design gráfico deva ser gerido não com base em uma estrutura estática e simétrica de poder, mas sim em uma estrutura dinâmica e assimétrica. Tal estrutura, empregando em cada um de seus níveis sistêmicos as mesmas quatro perspectivas do BSC, teria como elemento central inicialmente a perspectiva financeira, a qual só estaria sujeita ao rebaixamento caso duas das demais três perspectivas periféricas concordassem com um mesmo interesse em um jogo de turnos simultâneos. Isso significa que, apesar da decisão padrão de uma equipe ser tomada pelo representante da vontade dos acionistas, em cada etapa de um projeto, se houver a convergência das vontades dos demais grupos de stakeholders em uma votação cega, o novo representante eleito deve assumir a liderança da equipe até o próximo estágio do trabalho. Assim, teoricamente, cria-se um sistema dinâmico internamente consistente capaz de perceber e se adaptar aos diferentes tipos de recursos e ameaças externos, promover a sensação de pertencimento e empoderamento individual e, ainda, garantir a máxima eficiência estrutural.

Conforme exibe a Figura 6, tal heurística de tomada de decisão coletiva torna-se progressivamente mais coesa com o passar do tempo, uma vez que o feedback em relação ao sucesso ou fracasso das escolhas centrais 
em cada etapa proporciona o acúmulo de evidências materiais e, assim, a aprendizagem a respeito da utilidade das diferentes perspectivas individuais. Nesta imagem ilustrativa, após o término da primeira etapa projetual, elegeu-se, por exemplo, a perspectiva dos clientes como o novo foco do projeto, o qual manteve-se após o término da segunda etapa, mas o mesmo não ocorreu após o término da enésima etapa, momento em que se decidiu que a diretriz primária desse projeto seria a perspectiva dos processos internos. Quanto mais etapas estiverem presentes em um projeto, mais precisa será a triangulação do elemento que, em média, exerce melhor a tomada de decisão (GLUTH; RIESKAMP; BÜCHEL, 2013).

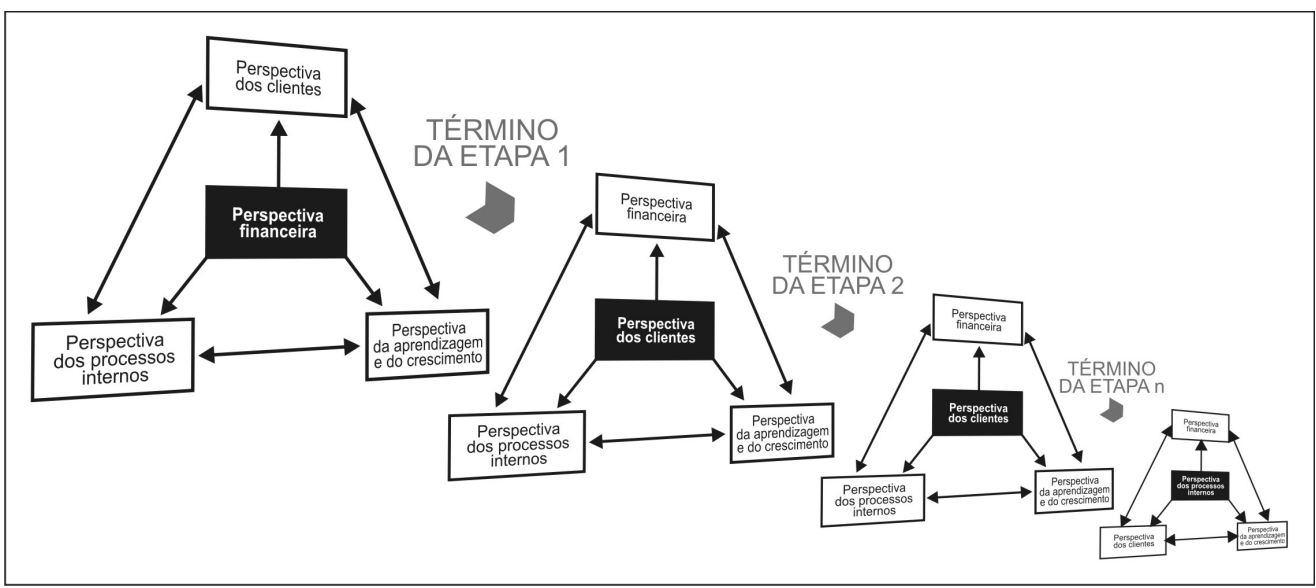

Figura 6. Heurística Dinâmica para a Tomada de Decisão Coletiva [Fonte: Autor]

Sugere-se para essa heurística as quatro perspectivas originalmente propostas para o BSC (KAPLAN; NORTON, 1992, 1993), pois, encontram-se nelas representantes de todos os principais stakeholders envolvidos em um grande projeto de design gráfico e, assim, triangula-se de maneira mais abrangente os interesses em jogo. Enquanto a perspectiva financeira descreve os interesses dos acionistas por meio de medidas em torno do lucro, a perspectiva do cliente caracteriza-se pela percepção de valor dos públicos atingidos por uma determinada organização, a perspectiva dos processos internos avalia os interesses dos gerentes, diretores e fornecedores, e a perspectiva do aprendizado e do crescimento descreve os atributos de interesse da equipe de designers ou funcionários em seu próprio ambiente de trabalho. Existem também outras perspectivas alternativas que poderiam ser utilizadas, mas, para se obter os benefícios referentes à tomada de decisão, é essencial que os representantes sempre se mantenham na quantia de quatro. Sendo assim, uma proposta alternativa de Wong, Lam e Chan (2009) sugere, por exemplo, as perspectivas estética, econômica, funcional e de construção para projetos gráficos de dimensões 
mais acanhadas, ou, em casos ainda menores, quatro pontos de vista quaisquer em uma sessão de brainstorming.

Havendo essa restrição numérica na quantidade de participantes ou interesses, a solução ótima para a hierarquização sistêmica dos grandes projetos de comunicação é, então, a adoção de uma estruturação fractal. Como pode ser visto na Figura 7, dentro de cada uma das diferentes perspectivas ou grandes interesses gerais, pode haver infinitos outros níveis de tomada de decisão, desde que todos eles espelhem a estrutura original. Desta forma, mesmo a decisão final ficando a cargo somente do representante central geral (top-down), a escolha desse representante, bem como de seus pares periféricos, reflete ao máximo os inúmeros interesses individuais de uma equipe (bottom-up), pois, cada nível sistêmico terá o seu próprio líder ou representante, especialista em sua própria área de atuação, para sanar os conflitos locais.

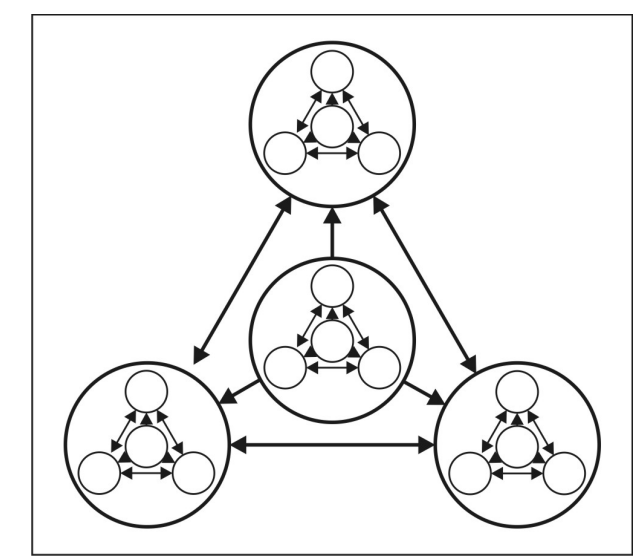

Figura 7. Estruturação Fractal da Heurística de Tomada de Decisão Coletiva. Fonte: Autor

Assim sendo, as funções básicas da proposta de heurística para gerir o equilíbrio dos interesses em equipes de design gráfico são quatro: (1) Atribuir diferentes poderes a cada elemento participante de um projeto; (2) Definir um mecanismo justo para a rotatividade das posições estruturais; (3) Garantir que o núcleo coletivo seja ocupado pela perspectiva que se mostra imediatamente mais eficaz; e (4) Tornar o interesse financeiro o centro inicial do sistema social. Com base nessas premissas, a convergência de um conjunto de escolhas ou estratégias individuais torna-se plausível ao longo da dinâmica projetual, a qual, apoia-se em um estado de equilíbrio de Nash, já que nenhum ator beneficiar-se-ia por uma mudança em sua conectividade. Destarte, concilia-se as capacidades de inovação e de estabilidade e, também, a permanência dos indivíduos em uma equipe com a eficiência dessa coletividade. 


\section{Considerações finais}

Uma vez que a única métrica comum em projetos de design gráfico, frequentemente, é a unidade de vontade ou de interesse próprio, percebe-se que a arquitetura dos seus próprios sistemas sociais depende, antes de mais nada, da percepção de valor que é utilizada como ponto de referência para a tomada de decisão dos diferentes indivíduos interagindo no mesmo contexto de competição. Tal estrutura, todavia, não é plenamente passiva, uma vez que ela também influencia os ganhos individuais advindos das externalidades gerais. Nisso, faz-se necessário um método para a gestão do equilíbrio dos interesses em equipes colaborativas de design, pois, do contrário, não se sustentam, simultaneamente, a satisfação e o desempenho individual com a inovação e a eficiência estrutural nessas coletividades.

A proposta deste artigo, então, consiste de uma heurística de rotatividade do poder de decisão central, o qual inicia-se na perspectiva financeira, mas pode vir a ser, também, as perspectivas do cliente, dos processos internos ou da aprendizagem e do crescimento. Quanto maior ou mais longo for o projeto, teoricamente, mais os designers individualmente seriam capazes também de discernir a perspectiva que melhor representa os interesses coletivos. Mesmo ainda sendo apenas uma proposição puramente teórica, especula-se que, por meio dessa dinâmica matematicamente coerente, as equipes de design gráfico sejam capazes de criar uma compreensão mais abrangente do processo de tomada de decisão geral e, assim, paradoxalmente, aproveitar o máximo de cada expertise individual.

Reconhece-se, porém, que nenhuma proposta teórica por si só é capaz de se provar útil ao exercício de uma prática profissional, sobretudo àquelas envolvidas com problemas pouco estruturados como é o caso do design gráfico, e, portanto, que a heurística relatada restringe-se ao campo da racionalidade. Futuras pesquisas, além de testarem empiricamente essa dinâmica de tomada de decisão coletiva, devem também discernir com mais precisão as diferentes perspectivas ótimas para serem empregadas em cada contexto social, propor métricas de acompanhamento da aprendizagem ocorrida em cada etapa projetual e, ainda, investigar o limite de fractalidade capaz de sustentar, de fato, o interesse e a sensação de pertencimento individual. Com base nessas novas investigações, finalmente, poder-se-á confirmar, ou não, que a resposta para a questão sobre o melhor trade-off entre centralidade e hiperconectividade em um sistema de trabalho projetual é: nem um, nem outro, mas o melhor de cada ao mesmo tempo. 


\section{Referências}

ALLAIS, M. Le comportement de l'homme rationnel devant le risque: Critique des postulats et axiomes de l'ecole americaine. Econometrica, v. 21, p. 503-546, 1953.

AMABILE, T. Social psychology of creativity: A consensual assessment technique. Journal of Personality and Social Psychology, v. 43, n. 5, p. 9971013, 1982.

BAXTER, M. Projeto de Prouto. São Paulo: Edgar Blucher, 1998.

BLOCH, F.; JACKSON, M. Definitions of equilibrium in network formation games. International Journal of Game Theory, v. 133, p. 83-110, 2006.

BOGACZ, R. Optimal decision-making theories: linking neurobiology with behaviour. TRENDS in Cognitive Sciences, v. 11, n. 3, p. 118-15, 2006.

DE MARTINO, B.; KUMARAN, D.; SEYMOUR, B.; DOLAN, R. Frames, biases, and rational decision-making in the human brain. Science, v. 313, p. 684-687, 2006.

FUDENBERG, D.; MASKIN, E. The folk theorem in repeated games with discounting or with incomplete information. Econometrica, v. 54, n. 3, p. 533-554, 1986.

FUENTES, R. A Prática do Design Gráfico: Uma metodologia criativa. São Paulo: Edições Rosari, 2006.

GLUTH, S.; RIESKAMP, J.; BÜCHEL, C. Deciding not to decide: Computational and neural evidence for hidden behavior in sequential choice. PLOS Computational Biology, v. 9, n. 10, p. e1003309, 2013.

HARDIN, G. The tragedy of the commons. Science, v. 162, n. 3859, p. $1243-$ $1248,1968$.

HARRIS, L. The Winners and Losers of the Zero Sum Game: The origins of trading profits, price efficiency and market liquidity. Working Paper, Marshall Business School, USC, Los Angeles, 1993. 
JACKSON, M.; WOLINSKY, A. A strategic model of social and economic networks. Journal of Economic Theory, v. 71, p. 44-74, 1996.

KAHNEMAN, D.; TVERSKY, A. Prospect theory: An analysis of decision under risk. Econometrica, v. 47, n. 2, p. 263-291, 1979.

KAPLAN, R.; NORTON, D. Putting the Balanced Scorecard to work. Harvard Business Review, p. 134-147, set-out, 1993.

KAPLAN, R.; NORTON, D. The Balanced Scorecard: Measures that drive performance. Harvard Business Review, 71-79, jan-fev, 1992.

KLEINSMANN, M.; VALKENBURG, R. Barriers and enablers for creating shared understanding in co-design projects. Design Studies, v. 29, p. 369386, 2008.

LEE, D. Decision Making: From Neuroscience to Psychiatry. Neuron, v. 78, p. 233-248, 2013.

LEE, D. Neural basis of quasi-rational decision making. Current Opinion in Neurobiology, v. 16, p. 191-198, 2006.

MARCONI, M.; LAKATOS, E. Fundamentos de Metodologia Científica. São Paulo: Atlas, 2007.

MATLIN, M. Psicologia Cognitiva. Rio de Janeiro: LTC, 2004.

MCCALLUM, D. et al. Competition and cooperation between groups and between individuals. Journal of Experimental Social Psychology, v. 21, p. 301-320, 1985.

NASH, J. Non-cooperative games. The Annals of Mathematics, v. 54, n. 2, p. 286-295, 1951.

PHILLIPS, P. Briefing: A gestão do projeto de design. São Paulo: Blucher, 2008.

RENEKE, J. A game theory formulation of decision making under conditions of uncertainty and risk. Nonlinear Analysis, v. 71, p. e1239e1246, 2009. 
RODRIGUES, W. O Balanced Scorecard da Petrobras: Indicadores de desempenho do downstream. 2006. Dissertação (Mestrado em Engenharia de Produção) - Pontifícia Universidade Católica do Rio de Janeiro. Rio de Janeiro: PUC-RIO, 2006.

SANDRONI, A. Does rational learning lead to Nash equilibrium in finitely repeated games? Journal of Economic Theory, v. 78, p. 195-218. 1998.

SHERIF, M. Superordinate goals in the reduction of intergroup conflict. The American Journal of Sociology, v. 63, n. 4, p. 349-356, 1958.

SHIH, S.; HU, T.; CHEN, C. A game theory-based approach to the analysis of cooperative learning in design studios. Design Studies, v. 27, p. 711-722, 2006.

WONG, F.; LAM, P.; CHAN, E. Optimising design objectives using the Balanced Scorecard approach. Design Studies, v. 30, p. 369-392, 2009.

YANG, M. Consensus and single leader decision-making in teams using structured design methods. Design Studies, v. 31, p. 345-362, 2010. 


\section{Como citar}

MERINO, Eugenio A.D; PINHEIRO, Igor R.; GOMEZ, Luiz S.R. A gestão dos conflitos de interesses em equipes de design gráfico conforme as teorias sobre a tomada de decisão. Arcos Design. Rio de Janeiro: PPD ESDI - UERJ. Vol. 9 Número 1 Junho 2016. pp. 84103. Disponível em: [http://www.e-publicacoes.uerj.br/index.php/ arcosdesign]

DOI

\section{(9) (1) (ब(}

A Revista Arcos Design está licenciada sob uma licença Creative Commons Atribuição - Não Comercial - Compartilha Igual 3.0 Não Adaptada. 